\title{
Thyroid Agenesis: A Case Report with Review of Literature
}

\author{
Eti Sthapak, Ujjwal L Gajbe, SP Wanjari, Vijai Datta Upadhyaya, Basant Kumar
}

\begin{abstract}
The thyroid gland, a highly vascular endocrine gland, is composed of two lateral lobes connected by a narrow median isthmus thus giving an ' $\mathrm{H}$ '-shaped appearance to the gland. Congenital thyroid abnormalities mostly include unilateral lobar agenesis, with or without involving the isthmus. We are reporting a case rudimentary right lobe with absence of isthmus. The knowledge of various developmental anomalies of the gland and variations in neurovascular relations will help the surgeon in better planning of a safe and effective surgery.
\end{abstract}

Keywords: Thyroid, Agenesis, Isthmus.

How to cite this article: Sthapak E, Gajbe UL, Wanjari SP, Upadhyaya VD, Kumar B. Thyroid Agenesis: A Case Report with Review of Literature. World J Endoc Surg 2012;4(3): 99-101.

\section{Source of support: Nil}

Conflict of interest: None

\section{INTRODUCTION}

Thyroid hemiagenesis is a rare anomaly. It was first reported in 1895 by Marshall ${ }^{1}$ who found the right lobe to be absent in one of the 60 childhood thyroid glands examined specifically to determine the type and frequency of anomalies of this gland. Hemiagenesis of the left lobe detected at surgery was reported from India by Das ${ }^{2}$ in 1962. In the literature, most of the patients reported to have thyroid hemiagenesis had accompanying thyroid disorders because the absence of one thyroid lobe usually does not cause clinical symptoms by itself. The true prevalence of thyroid hemiagenesis is not known, but it is estimated to be $0.02 \%$ in normal children. ${ }^{3}$ Thyroidal hemiagenesis is predominantly seen in females and left lobe is absent in most of the cases. ${ }^{4}$

\section{CASE REPORT}

During routine dissection of thyroid in male cadaver showed absence of the isthmus with rudimentary right lobe and slightly large left lobe (Fig. 1). The right lobe was rudimentary measuring $1 \mathrm{~cm}$ in length (Fig. 2) and $1 \mathrm{~cm}$ in width whereas left lobe was measuring $7 \mathrm{~cm}$ in length and $3.8 \mathrm{~cm}$ in width. Apex is directed toward the oblique line of thyroid cartilage and related to superior thyroid artery and external laryngeal nerve, the base is extended up to fifth, sixth tracheal rings, the base is related to inferior thyroid artery and recurrent laryngeal nerve. The location of thyroid gland was normal but the right lobe was rudimentary and the isthmus was absent. Normally isthmus connects the lobes lower part, it is about $1.25 \mathrm{~cm}$ transversely and vertically and is usually anterior to the second and third tracheal cartilages, though often higher, in the present case it is absent. Left lobe was supplied by the superior and inferior thyroid artery whereas as on right side only inferior thyroid artery was seen.

\section{DISCUSSION}

The size and shape of the thyroid gland is subject to much variation, as stated by Wood Jones. Literature is replete with a large number of variations of the gland. Thyroid hemiagenesis is a rare congenital anomaly with absence of a lobe or a lobe and the isthmus. Embryologically, it develops in the midline from the pharyngeal floor at the foramen cecum. ${ }^{5}$ The thyroid gland appears as an epithelial proliferation in the floor of the pharynx between trabeculum impar and the copula at a point later indicated by foramen cecum. Subsequently, thyroid gland descends in front of

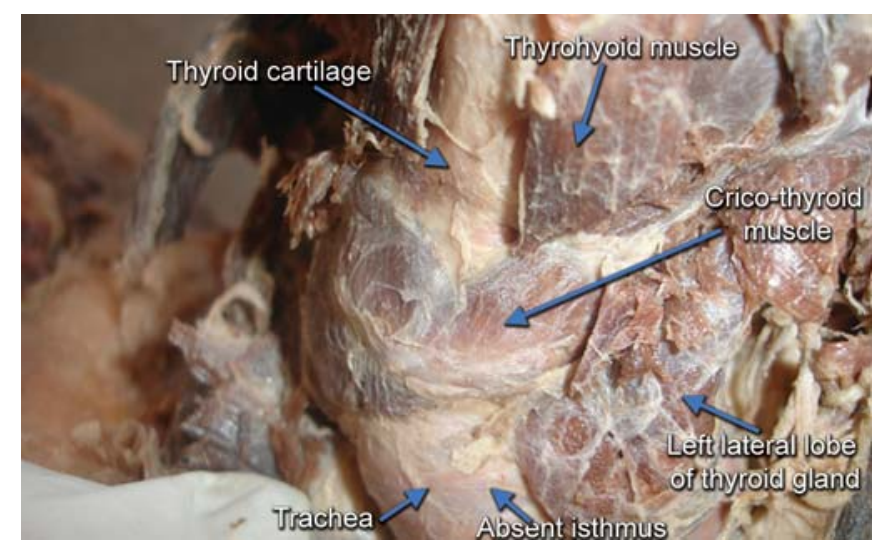

Fig. 1: Left lateral lobe of the thyroid with absent isthmus and thyroid cartilage

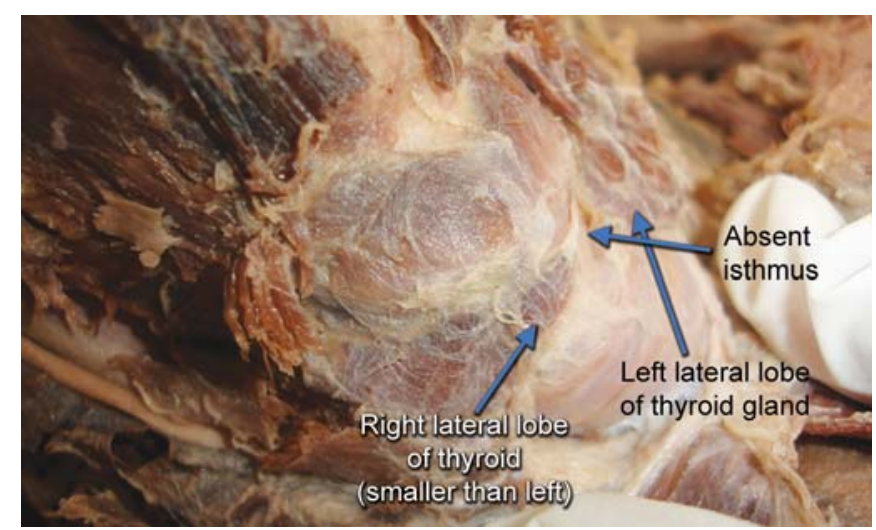

Fig. 2: The rudimentary right lobe of thyroid and absent isthmus 
the pharyngeal gut as bilobed diverticulum. During this migration, the thyroid remains connected to the tongue by a narrow canal, the thyroglossal duct, this duct normally disappears. ${ }^{6}$ Rarely, a high separation of thyroglossal duct can engender two independent thyroid lobes and pyramidal lobes with the absence of isthmus. ${ }^{7}$ Further developments, the thyroid gland decends in front of the hyoid bone and the laryngeal cartilages. It reaches its final position in front of the trachea in the 7th week. By then it has acquired a small median isthmus and two lateral lobes. The exact cause of hemiagenesis is not clear. It is thought to result from failure of the cells to migrate laterally resulting in agenesis of a part of the thyroid but it may result from disturbance of lobulation process either due to environmental or genetic insult and few authors have reported role of chromosome 22 in thyroid lobar agenesis.

The prevalence of the hemiagenesis of thyroid is ranged between 0.05 and $0.2 \%$ in most of the studies and is more prevalent in females ${ }^{8,9}$ and in most of the series left lobe is absent. ${ }^{10}$ Most of the descriptions in the literature are based on the screening of the thyroid by ultrasound in patients coming or thyroid abnormalities or screening in the iodine deficiency areas. Gursoy A et $\mathrm{al}^{8}$ in their study found that the prevalence of hemiagenesis of thyroid lobe was $0.25 \%$ in patients who presented with various thyroid disorders whereas its prevalence in normal population was only $0.025 \%{ }^{8}$ and it was the left lobe which was absent in all cases, as in our cases there is absence of isthmus along with rudimentary right lobe. Many workers claim that the absence of isthmus is quite rare in humans, ${ }^{11}$ and in adult animals, the isthmus is either present or absent. According to the studies by Braun et al the isthmus was missing in four cases of the 58 cadavers they studied. ${ }^{12}$ Won and Chung have reported that in $3 \%$ of the cases studied, the isthmus was absent and the lateral lobes of the thyroid were separated, ${ }^{13}$ though the absence of isthmus had been reported between 3 and $10 \%$. Pastor et al stated that absence of an isthmus can be associated with other types of dysorganogenesis, such as the absence of a lobe or the presence of ectopic thyroid tissue $^{14}$ as in our case the right lobe was rudimentary. Literature search showed that most common dysorganogenesis in cadaver is absence of isthmus followed by hemiagenesis ${ }^{15}$ of one of the thyroid lobe whereas the studied carried out in symptomatic or in normal population had showed that most common anomaly is absence of left lobe (80\%) followed by absence of isthmus. ${ }^{16}$

Per se, the morphological difference in the evolutionary origin should not result in any changes in thyroid function but studies has shown that the prevalence of hemiagenesis is more common in symptomatic patients than the normal population. ${ }^{6}$ Usually agenesis of isthmus is difficult to determine unless the patients refer for other thyroid diseases; though can be diagnosed via scintigraphy, ultrasonography, CT and MRI but all these investigations have their advantages and disadvantages. We have presented this case because though absence of isthmus have no impact on the thyroid function but if isthmus absence is diagnosed or suspected the individual must be screened for autonomous thyroid nodule; thyroiditis; primary carcinoma; neoplastic metastases and infiltrative diseases, such as amyloidosis.

\section{CONCLUSION}

Thyroid hemiagenesis is an uncommon presentation that is frequently asymptomatic and detected incidentally when imaging for another condition. Awareness of its existence can help prevent unnecessary interventions associated with incorrect assumptions in patient care and better understanding of anatomy of such cases may help the surgeon in proper dissection.

\section{REFERENCES}

1. Marshall CF. Variations in the form of the thyroid gland in man. J Ana Physiol 1895;29:234-39.

2. Das P. Congenital absence of one thyroid lobe. J Ind Med Assoc 1962;39:302-04.

3. Maiorana R, Carta A, Floriddia G, Leonardi D, Buscema M, Sava L, et al. Thyroid hemiagenesis: Prevalence in normal children and effect on thyroid function. J Clin Endocrinol Metab 2003;88(4):1534-36.

4. Mikosch P, Gallowitsch HJ, Kresnik E, Molnar M, Gomez I, Lind P. Thyroid hemiagenesis in an endemic goiter area diagnosed by ultrasonography: Report of sixteen patients. Thyroid 1999;9(11):1075-84.

5. Kaplaw EL, Shukla M, Hara H, Ito K. Developmental abnormalities of the thyroid. In: De Groot LJ (Ed). Endocrinology. Philadelphia: Saunders 1994;893-99.

6. Sadler TW. Head and neck. Langman's Med Embryol 2006; 10:270.

7. Sgalitzer KE. Contribution to the study of the morphogenesis of the thyroid gland. J Anat 1941;75:389-405.

8. Gursoy A, Anil C, Unal AD, Demirer AN, Tutuncu NB, Erdogan MF. Clinical and epidemiological characteristics of thyroid hemiagenesis: Ultrasound screening in patients with thyroid disease and normal population. Endocrine 2008 Jun 33(3):338-41.

9. Peña S, Robertson H, Walvekar RR. Thyroid hemiagenesis: Report of a case and review of literature. Indian J Otolaryngol Head Neck Surg 2011 Apr;63(2):198-200.

10. Wu YH, Wein RO, Carter B. Thyroid hemiagenesis: A case series and review of the literature. Am J Otolaryngol 2011 Sep 16.

11. Romanes GJ. Cunningham's Textbook of Anatomy (12th ed). Oxford: Oxford University Press, 1981;57-59, 286, 596-97.

12. Braun E, Windisch G, Wolf G, Hausleitner L, Anderhuber F. The pyramidal lobe: Clinical anatomy and its importance in thyroid surgery. Surg Radiol Anat 2007;29:21-27. 
13. Won HS, Chung IH. Morphologic variations of the thyroid gland in Korean adults. Korean J Phys Antropol 2002;15: 119-25.

14. Pastor VJF, Gil VJA, De Paz Fernández FJ, Cachorro MB. Agenesis of the thyroid isthmus. Eur J Anat 2006;10:83-84.

15. Korpal-Szczyrska M, Kosiak W, Swieton D. Prevalence of thyroid hemiagenesis in an asymptomatic schoolchildren population. Thyroid 2008 Jun;18(6):637-39.

16. Karabay N, Comlekci A, Canda MS, Bayraktar F, Degirmenci B. Thyroid hemiagenesis with multinodular goiter: A case report and review of the literature. Endocr J 2003 Aug;50(4):409-13.

\section{ABOUT THE AUTHORS}

\section{Eti Sthapak (Corresponding Author)}

Resident, Department of Anatomy, JLN Medical College, DMIMS Wardha (Meghe), Maharashtra, India, e-mail: etiupadhyaya@yahoo.co.in

\section{Ujjwal L Gajbe}

Professor and Head, Department of Anatomy, JLN Medical College DMIMS, Wardha (Meghe), Maharashtra, India

\section{SP Wanjari}

Professor, Department of Anatomy, JLN Medical College, DMIMS Wardha (Meghe), Maharashtra, India

\section{Vijai Datta Upadhyaya}

Assistant Professor, Department of Pediatric Surgery, SGPGIMS Lucknow, Uttar Pradesh, India

\section{Basant Kumar}

Assistant Professor, Department of Pediatric Surgery, SGPGIMS Lucknow, Uttar Pradesh, India 